\title{
Research and Application of the Novel Deep Plugging Method in the Oilfield
}

\author{
Juan Zhao" ${ }^{1,2,3}$, Hongfu Fan ${ }^{1,2,3}{ }^{*}$, Long Liu ${ }^{1,2,3}$, Yi Jia ${ }^{1,2,3}$ \\ ${ }^{1}$ School of Energy Resources, China University of Geosciences (Beijing), Beijing, China \\ ${ }^{2}$ Key Laboratory of Marine Reservoir Evolution and Hydrocarbon Enrichment Mechanism, Ministry of Education, \\ Beijing, China \\ ${ }^{3}$ Beijing Key Laboratory of Unconventional Natural Gas Geological Evaluation and Development Engineering, \\ Beijing, China \\ Email: ^13683007976@163.com
}

How to cite this paper: Zhao, J., Fan, H.F., Liu, L. and Jia, Y. (2019) Research and Application of the Novel Deep Plugging Method in the Oilfield. Journal of Materials Science and Chemical Engineering, 7, 10-19. https://doi.org/10.4236/msce.2019.71002

Received: December 18, 2018

Accepted: January 19, 2019

Published: January 22, 2019

Copyright () 2019 by author(s) and Scientific Research Publishing Inc. This work is licensed under the Creative Commons Attribution-NonCommercial International License (CC BY-NC 4.0).

http://creativecommons.org/licenses/by-nc/4.0/

\begin{abstract}
In long-term water drive reservoir, small dose and short radius profile control cannot meet the needs, so deep profile control and flooding are needed. During the placement and processing of conventional deep profile control and flooding agent, the zone classification formed by the changes of pressure field and fluid field are not taken into account. In order to better develop these reservoirs, we proposed a novel deep profile control method, that is, the iso-pressure drop gradient progressive deep profile control method. The key features of the method include: 1) the method took into account the reservoir pressure distribution; 2) it proposed a novel standard to divide the orders of zone; 3) the method has been successfully applied in 4 wells in China Oilfield. The method divided the formation into near wellbore zone, well-far zone and deep zone according to the drawdown curve. As each zone of the pressure gradient is different and therefore require different intensity of slug. Then design the agent slugs according to iso-pressure drop gradient rule, and the breakthrough pressure gradient of agent is equal to the formation pressure gradient, and it achieved the fluid diversion of whole course by combining the different intensity of blocking agent. The method was applied successfully in 2 wells in China Oilfield from May to November in 2008. The method can smartly improve the sweep efficiency, and field test shows that it can play a very good efficiency of reducing water and increasing oil production. This method is becoming more of a concern in the oilfield develop.
\end{abstract}

\section{Keywords}

Deep Profile Control, Heterogeneity, Pressure Distribution, Iso-Pressure Drop Gradient 


\section{Introduction}

In China, some reservoirs are characterized by severe heterogeneity, large porous channels and high water/oil mobility ratio. The water flooding is still the main way of oil field development. As reservoirs mature, oil production declines while water production rises. Excess and unwanted water production from these mature fields is one problem that has plagued the oil industry for decades [1] [2]. Excess water production is a frequent problem that occurs in mature reservoirs as a result of long time water-flooding. Such excess water production usually results in increased environmental concerns, increased levels of corrosion and scale and ultimately leads to early shut-in of wells that still contain significant volumes of hydrocarbons [3] [4] [5]. Currently, polymer flooding technology [6]-[13] is the proven tertiary oil recovery technique all over the world, however, the polymer solution readily crossflow [14] [15] [16] in thief zone. The crossflow causes an invalid injection [17] [18] [19]. For long-term water drive reservoir, high capacity channel well developed, the small dose and short radius profile control cannot meet the needs, so we need deep flooding [20] [21]. The crosslinked polymer gel is the most widely used chemicals for conformance control, especially for in-depth fluid diversion [22] Extensive using of cross linked polymer [23] [24] solution in high permeability oilfields can obtain good results. The existing deep flooding technology adopts multistage combination method to design the slugs, but not combine with the distribution of current pressure field and fluid field, mainly due to hardly gain the distribution of current dynamic pressure field and fluid field, and lack of means to divide steps, simultaneously lack the blocking agent which can migrate into the deep formation. Whether the profile control agent can stay in the formation depends on the formation pressure gradient. When the pressure gradient is greater than the strength of the plugging agent, plugging agent can't stay in the stratum and will be pushed into the deep part of the stratum. Optimizing and placing the blocking agent in different positions in the stratum in order to achieve progressive fluid diversion, already become a very promising direction [25]. The progressive deep flooding method is suit for the current stage of development, can further tap potential of remaining oil.

The paper divided layer according to the drawdown curve, and the method [26] is making the tangent of pressure gradient curve, the cut points correspond to the cutting points of near wellbore, well-far zone and deep zone, the division is shown in Figure 1. In general case, we only consider profile control $3 \mathrm{~m}$ away from the wellbore, which is due to high pressure gradient and short validity. As each zone of the pressure gradient is different and therefore require different intensity of slug. Combine the slugs of agent according to iso-pressure drop gradient rule, then screen each slug blocking agent, and at last optimize the lowest-cost combination. The study places the different intensity of plugging agent in different zone, which achieves the fluid diversion of whole course by combining the different intensity of plugging agent. The method can smartly improve 


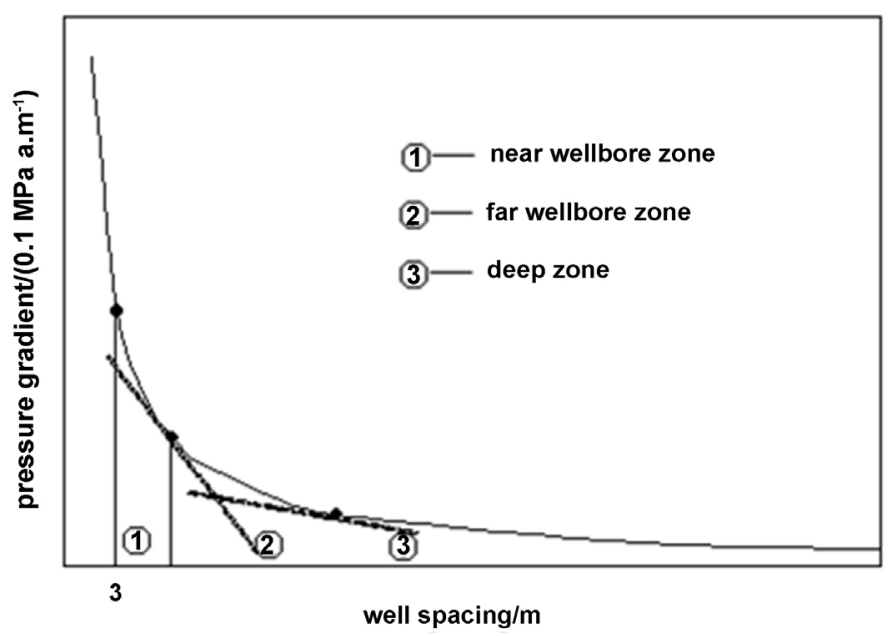

Figure 1. The schematic diagram of Stratigraphic division.

the sweep efficiency, and field test shows that the method can play a very good efficiency of reduce water and increase oil production.

\section{Materials and Method}

\subsection{Experiment Materials}

We use polymer gel as the plugging agent. The chemicals include HPAM (mol wt about $2220 \times 10^{4}$, solid content about $88 \%$, degree of hydrolysis about $27 \%$ ), chromium crosslinking agent, $\mathrm{NaCl}$ (analytical reagent, Laiyang Chemical). For the experimental water, we used the produced water according to the current polymer flooding situation of the oilfield, and after water quality analysis, its composition is shown in Table 1, and other materials shown in Table 2.

\subsection{Experiment Methods}

\subsubsection{Determination of Breakthrough Pressure Gradient}

The temperature is set at $65^{\circ} \mathrm{C}$, which is under the reservoir conditions, while the injection rate is $0.5 \mathrm{~mL} / \mathrm{min}$. Use breakthrough pressure gradient to evaluate the shut off capacity of plugging agent, and the flow schematic drawing follows Figure 2. The injection rate is $0.5 \mathrm{ml} / \mathrm{min}$. Test procedure: 1) Fill the pack with sand and weigh the dry weight; saturate it with water and measure the wet weight and calculate the pore volume; 2) Flood by water and measure the permeability after the pressure is stable; 3 ) Inject gel solution (add the crosslinking agent solution into the polymer solution), as much as one time pore volume, wait for gelling; 4) Water drive and record the pressure when the water starts flowing out, account the breakthrough pressure gradient.

\subsubsection{Determination of Recovery Increment}

The temperature is set at $65^{\circ} \mathrm{C}$, which is under the reservoir conditions, while the injection rate is $1 \mathrm{~mL} / \mathrm{min}$. Water displacement recovery increment refers to the difference of after injecting profiling agent and water drive, and use double 
Table 1. The composition of produced water.

\begin{tabular}{cccccccc}
\hline Composition & $\mathrm{Na}^{+}, \mathrm{K}^{+}$ & $\mathrm{Ca}^{2+}$ & $\mathbf{M g}^{2+}$ & $\mathbf{H C O}_{3}^{-}$ & $\mathbf{S O}_{4}^{2-}$ & $\mathrm{Cl}^{-}$ & Total salinity \\
\hline content/(mg/L) & 1493.81 & 64.63 & 13.06 & 325.37 & 10.29 & 2258.17 & 4165.33 \\
\hline
\end{tabular}

Table 2. List of materials required for experiments.

\begin{tabular}{|c|c|c|}
\hline Experiment & Core & Chemicals and Materials \\
\hline $\begin{array}{l}\text { Determination of } \\
\text { breakthrough } \\
\text { pressure gradient }\end{array}$ & $\begin{array}{l}\text { sand pack (sectional } \\
\text { area, } 4.9 \mathrm{~cm}^{2} \\
\text { length, } 20 \mathrm{~cm})\end{array}$ & $\begin{array}{l}\text { polymer, quartz sand ( } 60 \text { - } 80 \text { mesh size), } \\
\text { chromium crosslinking agent, constant flux pump, } \\
\text { core holder, precise pressure gauge, et al. }\end{array}$ \\
\hline $\begin{array}{l}\text { Determination of } \\
\text { recovery increment }\end{array}$ & $\begin{array}{l}\text { Two cylindrical cores } \\
\text { (sectional area, } 4.9 \mathrm{~cm}^{2} \text {; } \\
\text { length, } 9.8 \mathrm{~cm} \text { ). The } \\
\text { water permeability of } \\
\text { cores is } 500 \times 10^{-3}{\mu \mathrm{m}^{2} \text {, }} \text { and } 2000 \times 10^{-3} \mu^{2}\end{array}$ & $\begin{array}{l}\text { polymer, constant flux pump, core holder, pressure } \\
\text { sensor (Haian County Petroleum Science and } \\
\text { Technology Co., Ltd., Haian, China), precise } \\
\text { pressure gauge (Haian County Petroleum Science } \\
\text { and Technology Co., Ltd., Haian, China), graduate } \\
\text { (Haian County Petroleum Science and Technology } \\
\text { Co., Ltd., Haian, China), cylinder (Haian County } \\
\text { Petroleum Science and Technology Co., Ltd., } \\
\text { Haian, China), oil tank (Haian County } \\
\text { Petroleum Science and Technology Co., Ltd., } \\
\text { Haian, China), et al. }\end{array}$ \\
\hline
\end{tabular}

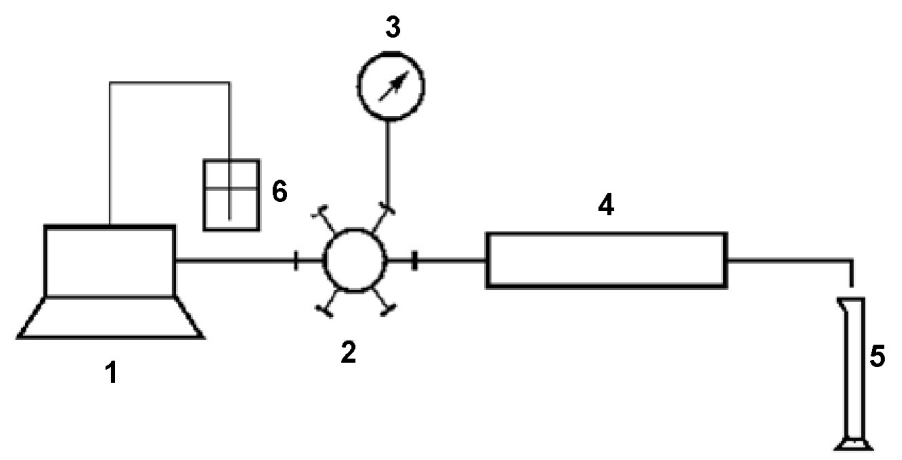

Figure 2. Flow chart of breakthrough pressure gradient. 1-constant-flux pump; 2-six-way valve; 3 -precision pressure gauge; $4-$ sand pack ; 5-measuring cylinder; 6-beaker.

core model to measure it, flow schematic drawing follows Figure 3 . The permeability of cores is $500 \times 10^{-3} \mu \mathrm{m}^{2}$ and $2000 \times 10^{-3} \mu^{2}$ respectively. Test procedures: 1) Fill the pack with sand and obtain the dry weight, before saturating it with water, measuring the wet weight and calculating the pore volume(short for $\mathrm{PV}$, it is equal to wet weight of cores minus dry weight of cores divided by water density. 2) separately inject the formation oil into the core to establish irreducible water saturation (short for Swi);3) install the two cores in parallel and flood with water until the water cut is $98 \%$; 4 ) inject the plugging agent to a maximum of $0.3 \mathrm{PV}$; 5) wait for gelling under formation temperature; 6) water drive until the water cut is $98 \%$; 7) record the fluid output volume of each core, then calculate the recovery increment. 


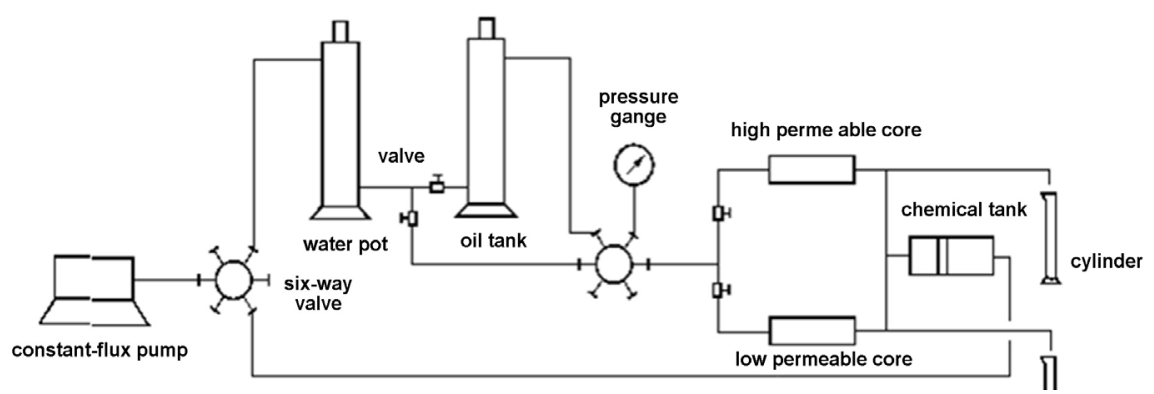

Figure 3. The recovery increment measuring device of double core model.

\section{Results and Discussion}

Compute the pressure gradient curve from the water well to oil well by numerical stimulation, and divide zones according to drawdown curve.

\subsection{Divided the Profile Control Zone}

The drop curve of the target well is shown in Figure 4. The stratum is divided by the tangent line of the formation pressure gradient curve, and the tangent point corresponds to the boundary point near the well area, the far well zone and the deep stratum. Follows as Figure 3, the near wellbore zone 3 - $8 \mathrm{~m}$; far wellbore zone 8 - $20 \mathrm{~m}$; deep zone $\geq 20 \mathrm{~m}$, in order to prevent shaft plugging, no plugging agent is set within 3 meters.

\subsection{Determination of Breakthrough Pressure Gradient Isogram}

Determine the breakthrough pressure gradient at different formulations of plugging agents. Mark the breakthrough pressure gradient on the map area, and connect the equivalent point, then draw the breakthrough pressure gradient isogram, follows as Figure 5. The data unit is $\mathrm{MPa} / \mathrm{m}$, and with the increase of reactant concentration, the breakthrough pressure gradient increases in Figure 5 , and the range is $0.015 \mathrm{MPa} / \mathrm{m}-3.1 \mathrm{MPa} / \mathrm{m}$.

\subsection{Slugs Combination Optimization Design}

\subsubsection{Optimization of the Slug Combination}

Determine the recovery increment of blocking agent with different volume, calculate the input-output ratio, and optimize the combination. Hypothetic the oil price is $¥ 2500$ per ton, the blocking agent is $¥ 80$ per square, and the other investment is twice the cost of blocking agent. Table 3 presents the Effect of slug size on input-output ratio, when the injection rate is $0.3 V_{\mathrm{p} \text { (thief zone), the in- }}$ put-output ratio attain smallest, have better economic benefit, and cost is opposite lower.

\subsubsection{Optimization Model}

According to geological reservoir data, the permeability of the thief zone is 2 $\mu \mathrm{m}^{2}$, the porosity is $30 \%$, thickness is $h$, well spacing $R_{\mathrm{e}}=100 \mathrm{~m}$, wellbore $R_{\mathrm{w}}=$ $0.08 \mathrm{~m}$. When injecting 0.3 PV blocking agent, calculate entrance depth $r$. 

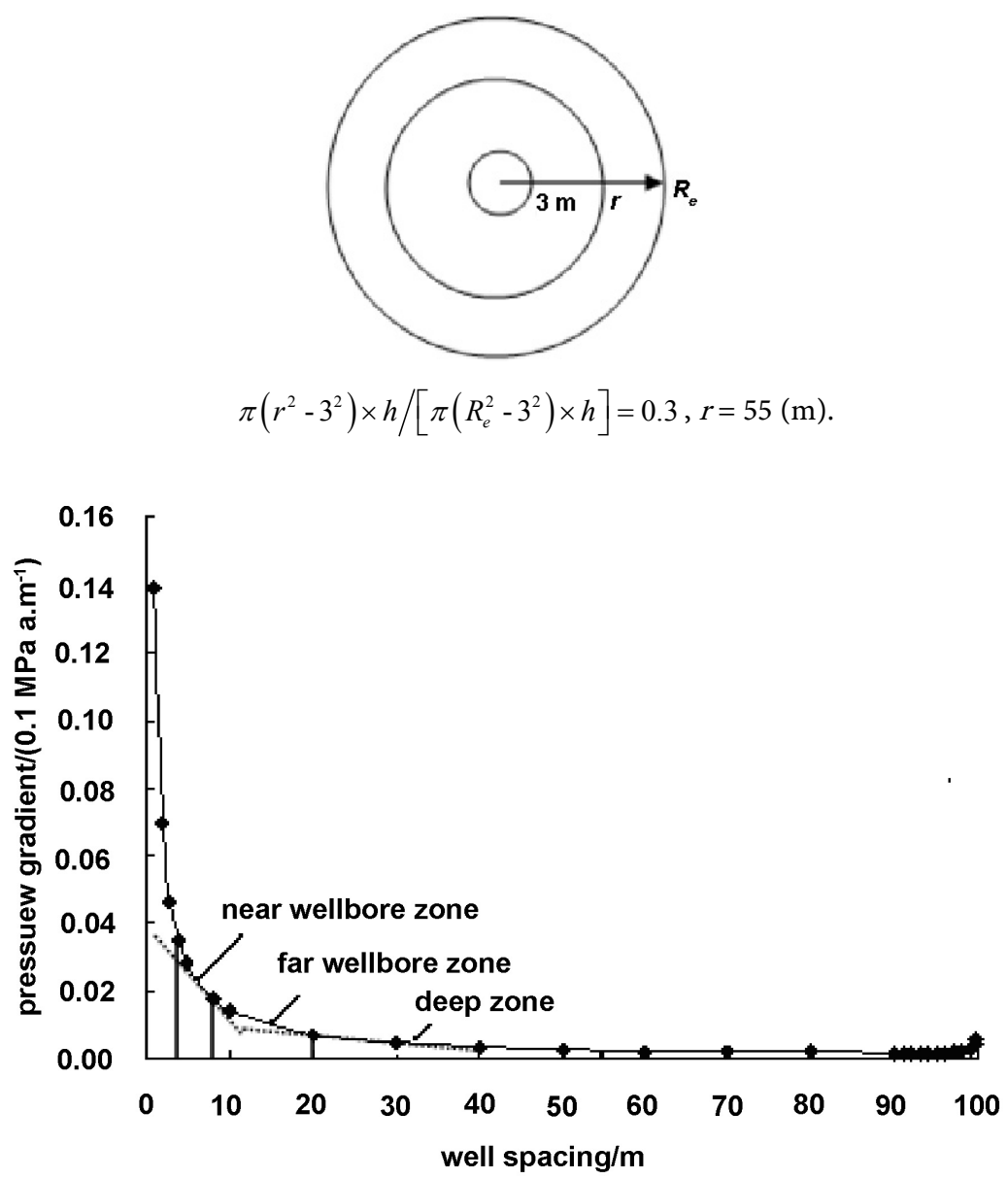

Figure 4. The pressure gradient curve of injection well.

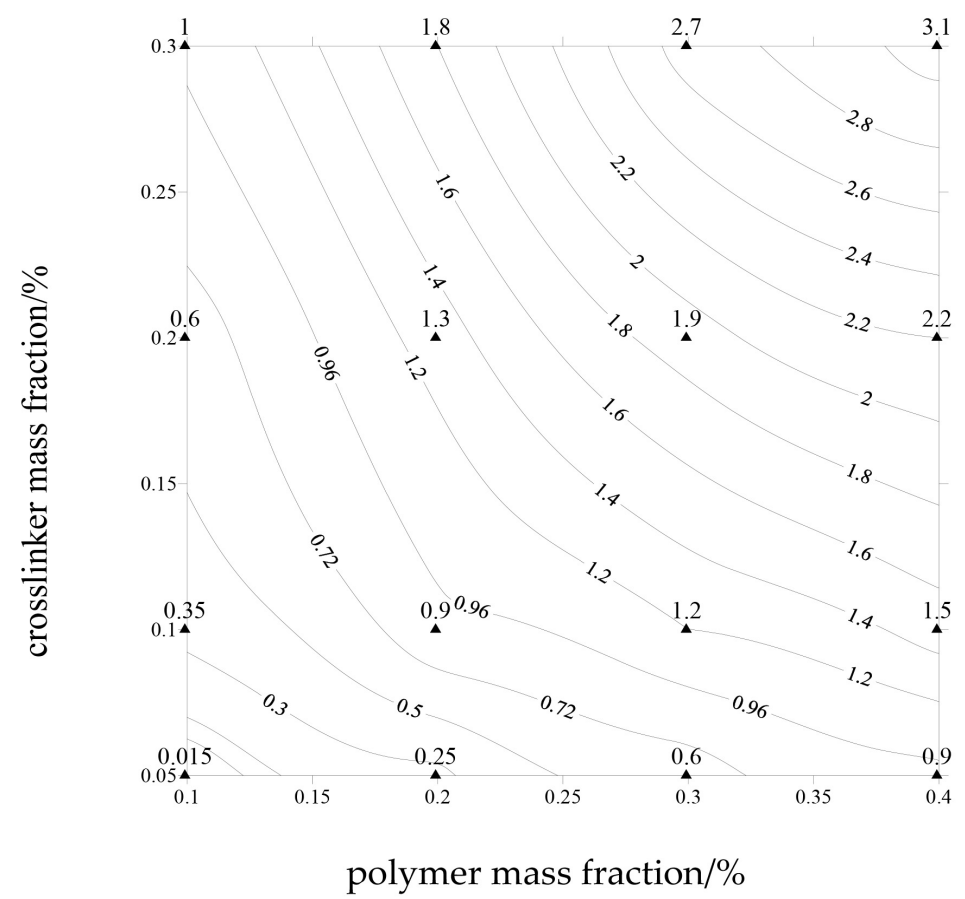

Figure 5. The breakthrough pressure gradient isogram of gel. 
Table 3. Effect of slug size on input-output ratio.

\begin{tabular}{cccc}
\hline Sample & Slug size/PV & $\mathrm{E}_{\mathrm{o}}-\mathrm{E}_{\mathrm{w}} / \%$ & Input-output ratio \\
\hline 1 & 0.1 & 8 & $1: 25.0$ \\
2 & 0.2 & 17 & $1: 26.6$ \\
3 & 0.3 & 28 & $1: 29.2$ \\
4 & 0.4 & 35 & $1: 27.3$ \\
5 & 0.5 & 38 & $1: 23.8$ \\
\hline
\end{tabular}

According to the formation conditions above mentioned, the entrance depth is $55 \mathrm{~m}$, so the profile control range is $3-55 \mathrm{~m}$. The blocking agent is divided into three slugs as follows in Figure 6. In order to ensure the agent can effectively plug formation, choose the maximum pressure gradient of each slug as the blocking agent required strength, namely the breakthrough pressure gradient of third slug is the pressure gradient when well spacing is $3 \mathrm{~m}$, the breakthrough pressure gradient of second slug is the pressure gradient when well spacing is 8 $\mathrm{m}$, and the breakthrough pressure gradient of first slug is the pressure gradient when well spacing is $20 \mathrm{~m}$.

In the actual displacing process, the strength loss of plugging agent is affected by perforation, ground flow, well head, well spacing and so on, and the perforation loss attains $40 \%$. Considering various factors, improve gel strength to 3 times of theoretical strength. The breakthrough pressure gradient of near wellbore zone is $1.4 \mathrm{MPa} \cdot \mathrm{m}^{-1}$, the breakthrough pressure gradient of far wellbore zone is $0.6 \mathrm{MPa} \cdot \mathrm{m}^{-1}$, and the breakthrough pressure gradient of deep zone is 0.2 $\mathrm{MPa} \cdot \mathrm{m}^{-1}$. Select a series of formulation from the breakthrough pressure gradient isogram of gel, and optimize the synergy follows as Table 4. The best combination is: the first slug is $0.18 \%$ polymer and $0.10 \%$ crosslinker, the second slug is $0.22 \%$ polymer and $0.12 \%$ crosslinker, the third slug is $0.24 \%$ polymer and $0.14 \%$ crosslinker.

\section{Conclusions}

1) The iso-pressure drop gradient progressive deep profile control method took into account the reservoir pressure distribution. Classify zones according to drawdown curve, and divide the formation into near wellbore zone, well-far zone and deep zone.

2) Draw the breakthrough pressure gradient isogram of gel, the data show that with the increase of reactant concentration, the breakthrough pressure gradient increases, and the range is $0.015 \mathrm{MPa} / \mathrm{m}-3.1 \mathrm{MPa} / \mathrm{m}$.

3) Combine the slugs of plugging agent according to iso-pressure drop gradient rule, screen each slug blocking agent, and optimize the lowest-cost combination. Optimized volume of blocking agent is $0.3 \mathrm{PV}$, and the profile control range is 3 - $55 \mathrm{~m}$ according to optimization model. The best combination is: the first slug is $0.18 \%$ polymer and $0.10 \%$ crosslinker, the second slug is $0.22 \%$ 


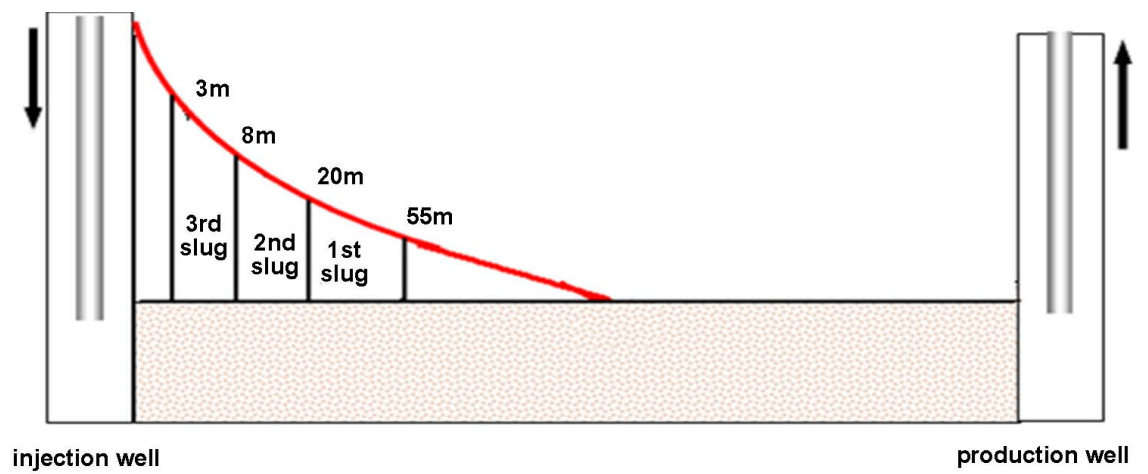

Figure 6. The schematic diagram of gel slug.

Table 4. The slug optimization of gel.

\begin{tabular}{ccccc}
\hline slug & $\begin{array}{c}\text { profile control } \\
\text { zone } / \mathrm{m}\end{array}$ & $\begin{array}{c}\text { pressure gradient } \\
/\left(\mathrm{MPa} \cdot \mathrm{m}^{-1}\right)\end{array}$ & $\begin{array}{c}\text { breakthrough pressure } \\
\text { of gel } /\left(\mathrm{MPa} \cdot \mathrm{m}^{-1}\right)\end{array}$ & $\begin{array}{c}\text { optimized } \\
\text { formulation }\end{array}$ \\
\hline Third slug & $3-8$ & 0.5 & 1.5 & $0.24 \% \mathrm{a}+0.14 \% \mathrm{~b}$ \\
Second slug & $8-20$ & 0.2 & 0.6 & $0.22 \% \mathrm{a}+0.12 \% \mathrm{~b}$ \\
First slug & $20-55$ & 0.08 & 0.25 & $0.18 \% \mathrm{a}+0.1 \% \mathrm{~b}$ \\
\hline
\end{tabular}

(a-ploymer, $\mathrm{b}-$ crosslinker).

polymer and $0.12 \%$ crosslinker, the third slug is $0.24 \%$ polymer and $0.14 \%$ crosslinker.

\section{Conflicts of Interest}

The authors declare no conflict of interest.

\section{References}

[1] Liu, Y., Zhu, M., Liu, X., et al. (2006) Hans-JuergenHigh Clay Content NanoComposite Hydrogels with Surprising Mechanical Strength and Interesting Deswelling Kinetics. Polymer, 47, 1-5. https://doi.org/10.1016/j.polymer.2005.11.030

[2] Alhuraishawy, A.K., Bai, B., Imqam, A., et al. (2018) Experimental Study of Combining Low Salinity Water Flooding and Preformed Particle Gel to Enhance Oil Recovery for Fractured Carbonate Reservoirs. Fuel, 214, 342-350. https://doi.org/10.1016/j.fuel.2017.10.060

[3] Hua, Z., Lin, M., Dong, Z., et al. (2014) Study of Deep Profile Control and Oil Displacement Technologies with Nanoscale Polymer Microspheres. Journal of Colloid \& Interface Science, 424, 67-74. https://doi.org/10.1016/j.jcis.2014.03.019

[4] Kotlar, H.K., Olav Selle, S., et al. (2007) Enhanced Oil Recovery by COMB-Flow: Polymer Floods Revitalized.

[5] Du, Y. and Guan, L. (2004) Field-Scale Polymer Flooding: Lessons Learnt and Experiences Gained during Past 40 Years.

[6] Wang, Q.M., Liao, G.Z., Niu, J.G., et al. (1999) Theoretical Research on Polymer Flooding. Petroleum Geology \& Oilfield Development in Daqing, 18, 1-5.

[7] Lee, S., Kim, D.H., Huh, C., et al. (2009) Development of a Comprehensive Rheological Property Database for EOR Polymers. Proceedings of the SPE Annual Technical Conference and Exhibition, New Orleans, 4-7 October 2009. 
https://doi.org/10.2118/124798-MS

[8] Seright, R.S. (2016) How Much Polymer Should Be Injected During a Polymer Flood? Review of Previous and Current Practices. SPE Journal, 1-18

[9] Huang, B., Zhang, W., Xu, R., et al. (2017) A Study on the Matching Relationship of Polymer Molecular Weight and Reservoir Permeability in ASP Flooding for Duanxi Reservoirs in Daqing Oil Field. Energies, 10, 1-10. https://doi.org/10.3390/en10070951

[10] Alsofi, A.M. and Blunt, M.J. (2014) Polymer Flooding Design and Optimization under Economic Uncertainty. Journal of Petroleum Science and Engineering, 124, 46-59. https://doi.org/10.1016/j.petrol.2014.10.014

[11] Zhu, D., Wei, L., Wang, B., et al. (2014) Aqueous Hybrids of Silica Nanoparticles and Hydrophobically Associating Hydrolyzed Polyacrylamide Used for EOR in High-Temperature and High-Salinity Reservoirs. Energies, 7, 3858-3871. https://doi.org/10.3390/en7063858

[12] Liu, S., Shen, A., Qiu, F., et al. (2017) Matching Relationship and Alternating Injection for Polymer Flooding in Heterogeneous Formations: A Laboratory Case Study of Daqing Oilfield. Energies, 10, 1018. https://doi.org/10.3390/en10071018

[13] Liu, B., Sun, X.Z., Wang, K., et al. (2007) Flooding by High-Concentration Polymer Doubled Oil Recovery of Common Polymer on Field Test with $20 \%$ Closed to the Result of Laboratory Test in Daqing.

[14] Azarshin, S., Moghadasi, J., Aboosadi, Z.A., et al. (2017) Surface Functionalization of Silica Nanoparticles to Improve the Performance of Water Flooding in Oil Wet Reservoirs. Energy Exploration \& Exploitation, 35, 685-697. https://doi.org/10.1177/0144598717716281

[15] Abedi, B., Ghazanfari, M. and Kharrat, R. (2012) Experimental Study of Polymer Flooding in Fractured Systems Using Five-Spot Glass Micromodel: The Role of Fracture Geometrical Properties. Energy Exploration \& Exploitation, 30, 689-706. https://doi.org/10.1260/0144-5987.30.5.689

[16] Sun, P.X. (2012) A Fuzzy Method to Judge Water Passages with Ineffective Injection-Production for Heterogeneous Sandstone Reservoir. Advanced Materials Research, 524-527, 1306-1309.

[17] Liu, L., Song, K., Pi, Y., et al. (2010) Notice of Retraction Recognize the Low-Efficiency Water Passage in Multilayer Non-Uniform Reservoir with Fuzzy Evaluation. International Conference on Advanced Computer Control, Singapore, 5, 139-141.

[18] Paradis, C.J., Dixon, E.R., Lui, L.M., et al. (2018) Improved Method for Estimating Reaction Rates during Push-Pull Tests. Ground Water.

[19] Zhang, T., Su, L., Liu, J., et al. (2009) Research and Development Trend of Profile Technology on the Deep of Gel. Oil-Gasfield Surface Engineering, 28, 26-27.

[20] Wu, J.C., Wang, Z., Zhao, Y., et al. (2013) Study on the Evaluation Method of Deep Profile Control and Flooding Effect. Advanced Materials Research, 712-715, 773 777. https://doi.org/10.4028/www.scientific.net/AMR.712-715.773

[21] Mattias, S. and Einar, N. (2013) Methods and Systems for Streamer Depth Profile Control. American Patent, US8573050.

[22] Liu, Y., Bai, B. and Shuler, P.J. (2006) Application and Development of Chemical-Based Conformance Control Treatments in China Oil Fields. SPE 99641.

[23] Li, M., Wang, A., Yu, X., et al. (2007) The Flowing Diversion Mechanism of Linked Polymer Solution. Acta Petrolei Sinica (Petroleum Processing Section), 23, 32-35.

[24] Dai, C., Zhao, J., Jiang, H., et al. (2010) A Study of Alternative Injection of Anionic 
and Cationic Polymer on Deep Profile Control in Low Permeability Formations. Acta Petrolei Sinica, 31, 440-444.

[25] Tian, M., Di, G., Zeng, M., et al. (2016) High Capacity Channel Recognition and Profile Control and Flooding Methods in Offshore Oilfield. Petrochemical Industry Application, 35, 1-4.

[26] Dai, C., Wang, L., Zhao, J., et al. (2011) Iso-Pressure Drop Gradient Progressive Deep Profile Control and Flooding Method. China Patent, 201010515631. 